\title{
Local anaesthetic medication for the treatment of asthma
}

\section{Rodrigo A Siqueira, Jorge CS Costa/*, Renato SB Cordeiro, Magda F Serra, Patrícia MR e Silva, Marco A Martins/ ${ }^{+}$}

Laboratório de Inflamação, Departamento de Fisiologia e Farmacodinâmica, Instituto Oswaldo Cruz-Fiocruz, Av. Brasil 4365 , 21040-900 Rio de Janeiro, RJ, Brasil *Departamento de Síntese, Far-Manguinhos-Fiocruz, Rio de Janeiro, RJ, Brasil

It is presumed that drugs able to prevent bronchial spasm and/or inflammation may have therapeutic potential to control asthma symptoms. The local anaesthetic lidocaine has recently received increased attention as an alternative form of treatment for asthmatic patients. This paper reviews the major findings on the topic and summarizes the putative mechanisms underlying the airway effects of local anaesthetic agents. We think that lidocaine extends the spectrum of options in asthma therapy, probably by counteracting both spasmogenic and inflammatory stimuli in the bronchial airways. The possibility of development of new anti-asthma compounds based on the synthesis of lidocaine derivatives is also on the horizon.

Key words: local anaesthetic - lidocaine - inflammation - asthma

Asthma is a chronic inflammation of the lung airways caused by environmental factors in genetically predisposed individuals. Episodic airway obstruction and reversible bronchial hyperresponsiveness to non specific irritants are the major symptoms of the disease, whose prevalence has remarkably increased worldwide over the past two decades despite important advances in therapy (Busse \& Rosenwasser 2003, Kay 2003, Barnes 2004). Among the potential reasons for causing the increase in asthma prevalence are changes in the environment due to improved hygiene (Umetsu et al. 2002), and lack of adherence to therapy by patients, as well as by physicians who do not always follow guidelines on the established antiinfammatory therapy in asthma (Apter \& Szefler 2004, Barnes 2004). Most of asthmatic patients are atopic, i.e., they have a genetic predisposition to produce high levels of imunoglobulin (Ig) E against environmental antigens and to mount an allergic inflammatory response. Inflammation is indeed central in the pathogenesis of asthma. The antigen activates mast cells and $\mathrm{T}_{\mathrm{H}} 2$ cells in the airways, which in turn release preformed and neosynthetised proinflammatory substances, including vasoactive amines, lipid mediators and interleukins 4, 5, 9 and 13, deeply implicated in the early and late phase reactions (Barnes 2004). An interesting aspect of the asthma pathogenesis is the strong $\mathrm{T}_{\mathrm{H}} 2$ response in the airway mucosa resulting in accumulation of a large number of eosinophils in tissue locations (Umetsu et al. 2002). Experimental and clinical observations have linked eosinophil derivatives with asthma dysfunctions such as epithelial cell damage and airway hyperresponsiveness. Other pivotal pathological changes that appear to be associated with eosinophils include subepithelial fibrosis, increased airway smooth

Financial Support: Faperj, CNPq, PDTIS-Fiocruz ${ }^{+}$Corresponding author. E-mail: mmartins@ioc.fiocruz.br Received 8 November 2004

Accepted 30 December 2004 muscle mass, angiogenesis and increased mucus production caused by goblet-cell and submucosal-gland hyperplasia (Busse \& Rosenwasser 2003, Payne et al. 2003, Barnes 2004). Therefore it is presumed that drugs able to prevent recruitment and/or activation of mast cells, $\mathrm{T}_{\mathrm{H}} 2$ cells and/or eosinophils may have therapeutic potential to control asthma.

\section{Current treatment strategies}

It is a clinical consensus that every patient with persistent asthma, regardless of disease severity, should use a daily controller medication (Redding \& Stoloff 2004). The therapeutic arsenal for asthma is relatively ample, basically consisting of two classes of drugs: (i) the bronchodilators, including inhaled long-acting $\beta_{2}$-agonists (salmeterol and formoterol), inhaled anticholinergics (ipratropium bromide and tiotropium bromide) and theophylline (slow-release theophylline and aminophylline); and (ii) the anti-inflammatory agents, including inhaled glucocorticosteroids (budesonide, fluticasone propionate, beclomethasone dipropionate and mometasone), antileukotrienes (montelukast, pranlukast and zafirlukast), cromones (sodium cromoglycate and nedocromil sodium) and anti-IgE (omalizumab). Inhaled glucocorticosteroids is by far the most effective treatment available for the control of mild, moderate and severe asthma (Barnes 2004). They inhibit the transcription of interleukins such as IL-4, IL-5, IL-13 and $\beta$ chemokines, and it is likely that switching off these key interleukins strongly contributes to the glucocorticosteroid efficacy in controlling asthma (Caramori \& Adcock 2003, Barnes 2004). However, concerns regarding its long-term administration and steroidresistance have provided pivotal motivation for discovering new asthma therapies. Treatment with combination inhalers containing a glucocorticosteroid and a long-acting $\beta_{2}$-agonist is becoming now the gold standard therapy for asthma. The $\beta_{2}$-agonist acts by binding to specific receptors expressed along the surface of the bronchial smooth muscle cells. This agonist binding activates a complex intracellular cascade of events that elevates cyclic AMP levels, leading to decrease in intracellular cal- 
cium, smooth muscle relaxation and bronchodilation (Shore $\&$ Drazen 2003). Despite being the most effective way of opening the airways and providing relief in the event of a severe asthma attack, the use of $\beta_{2}$-agonist as monotherapy is no longer recommended, since a number of studies have demonstrated that asthmatics who are chronically treated with bronchodilating $\beta$-agonists alone sometimes experience a worsening of their condition (Lazarus et al. 2001, Sears 2002, Ellis 2003).

\section{Local anaesthetics and allergic inflammation}

Local anaesthetics block voltage-gated sodium channels in peripheral nerves causing reversible inhibition of impulse transmission and blockade of neuronal function in a circumscribed area of the body (Tetzlaff 2000). Lidocaine is largely used in clinic as a short-acting local anaesthetic and antiarritmic agent (Tetzlaff 2000). Interestingly, lidocaine also inhibits the function of non-excitable cells, particularly inflammatory cells, such as neutrophils, eosinophils, macrophages, mast cells and $\mathrm{T}_{\mathrm{H}} 2$ cells, raising the promising possibility of alternative clinical applications on the control of chronic inflammatory diseases, including asthma (Hunt et al. 1996, Ohnishi et al. 1996, Okada et al. 1998, Hollmann \& Durieux 2000, Tanaka et al. 2002).

Ohnishi et al. (1996) incidentally discovered that concentrations of lidocaine as high as $10 \mathrm{mM}$ could be detected in the broncoalveolar lavage fluids recovered from asthma patients subjected to bronchoscopy under lidocaine topical anesthesia, and that such an effluent was a strong inhibitor of eosinophil viability in vitro. It was further demonstrated that lidocaine preferentially inhibited survival and activation of human eosinophils stimulated by cytokines, such as IL-5, IL-3 and GM-CSF, in a concentration dependent-manner $\left(\mathrm{IC}_{50} \cong 110 \mu \mathrm{M}\right)$. Such an effect did not seem to be accounted for by the blockade of sodium channels and could not be explained by an action on either cytokine receptor expression or cytokine-induced protein tyrosine phosphorilation (Ohnishi et al. 1996, Okada et al. 1998). Of note, these effects were not due to nonspecific cytotoxicity either, since (i) lidocaine inhibited eosinophil survival by causing apoptosis rather than necrosis; (ii) the mechanism of cell death was clearly time-dependent, requiring at least $24 \mathrm{~h}$ of exposure to lidocaine; and (iii) eosinophil survival and superoxide production induced by IgG, PAF or PMA were not modified by lidocaine, indicating that this local anaesthetic was not a general inhibitor of eosinophils (Okada et al. 1998). Other local anaesthetic agents such as tetracaine, dibucaine, benoxinate, procaine and bupivacaine also inhibited IL-5-evoked eosinophil survival in vitro but their pro-apoptotic performance did not reflect their respective anaesthetic potencies (Okada et al. 1998). It is well established that lidocaine at high concentrations can also block $\mathrm{K}^{+}$channels (Illek et al. 1992, Yoneda et al. 1993, Olschewski et al. 1996). Therefore, Bankers-Fulbright and coworkers studied the effect of three classes of $\mathrm{K}+$ channel blockers and reported that the sulfonylureas including glyburide, tolbutamide, and glipizide (one class of $\mathrm{K}+$ channel blockers) were the only ones able to mimic the effect of lidocaine on the inhibition of cytokine-mediated eosinophil survival and superoxide production in vitro. Similar functions of sulfonylureas and lidocaine suggested that these agents might be working through a similar mechanism - blockade of $\mathrm{K}^{+}$channel in order to evoke apoptosis of eosinophils (BankersFulbright et al. 1998).

\section{Clinical findings with lidocaine treatment}

Since eosinophils are expected to play a pivotal role in the pathogenesis of asthma, studies on the putative beneficial effect of nebulized lidocaine in adults and children with asthma have been carried out. Administration of nebulized lidocaine four times daily in 20 adult patients with severe asthma, who had side effects of exogenous hypercortisolism, allowed for the complete elimination of steroid treatment in 13 of 20 patients (Hunt et al. 1996). A pilot study involving six pediatric patients with severe asthma added support to the interpretation that nebulized lidocaine in doses of 40 to $100 \mathrm{mg}$ ( 0.8 to $2.5 \mathrm{mg} / \mathrm{kg}$ / dose) four times daily had indeed steroid-sparing actions (Decco et al. 1999). The results indicated that during a mean of 11.2 months of therapy (range 7 to 16 months) 5 of the 6 patients completely discontinued their oral steroids within an average time of 3.4 months. Similar findings were also reported by Rosario and coworkers, while treating a 12-year-old severe steroid-dependent asthmatic with nebulized lidocaine (Rosario et al. 2000). The side effects observed in these patients were limited to transient oropharyngeal anaesthesia and bitter taste.

In a more recent evaluation, Hunt et al. (2004) reported the results of a placebo-controlled 8-week study in 50 adult subjects with mild-to-moderate asthma. The patients were randomized ( 25 receiving lidocaine and 25 receiving placebo) and their inhaled steroids were progressively withdrawn over 4 weeks. The analysis revealed a significant benefit for lidocaine treatment $(4 \%, 100 \mathrm{mg})$ four times daily compared with placebo (saline), particularly concerning $\mathrm{FEV}_{1}$ symptom scores, night-time awakening, $\beta$ agonist use, and blood eosinophils. There were no serious adverse effects in either group, but 15 subjects (9 receiving lidocaine and 6 receiving placebo) did not complete the full 8-week trial. Reasons for withdrawal included worsening asthma symptoms (4 receiving lidocaine and 6 receiving placebo) and treatment intolerance ( 4 receiving lidocaine). From the latter group, one had a cold feeling in the throat, one reported a feeling of claustrophobia, one had cough, one had wheezing after lidocaine, and only the last presented a $16 \%$ decrease in $\mathrm{FEV}_{1}$ (Hunt et al. 2004). In line with previous studies, Harrison and Tattersfield (1998) reported that patients with mild-tomoderate asthma did not bronchoconstrict significantly more than to $0.9 \% \mathrm{NaCl}$ (saline). However, the possibility that patients with more severe asthma might have more marked bronchoconstriction could not be discarded. It should be emphasized that at least five single-dose studies have demonstrated broncoconstriction following lidocaine inhalation (Miller \& Awe 1975, Weiss \& Patwardhan 1977, Fish \& Peterman 1979, McAlpine \& Thomson 1989, Bulut et al. 1996), indicating that the putative use of lidocaine for the treatment of asthma should be investigated with caution. 


\section{Effects of lidocaine on the airways}

The effects of lidocaine on the airways are heterogeneous and complex. It is well established that in patients with asthma, airway instrumentation such as endotracheal intubations can cause life-threatening bronchospasm (Caplan et al. 1990), and that lidocaine when administered either intravenously or as an aerosol significantly attenuates that sort of reflex bronchoconstriction (Groeben et al. 1999). Inhaled lidocaine can also diminish the response to an inhalational provocation with hyperosmolar saline solution (Makker \& Holgate 1993), histamine (Groeben et al. 2000), water (Loehning et al. 1976) and under conditions of exercise-induced asthma (Enright et al. 1980). On the other hand, a number of studies has pointed out that aerosolization of lidocaine itself produces an initial bronchoconstriction in a significant proportion of patients with asthma and hyperirritable airways, as attested by reduction in $\mathrm{FEV}_{1}$ and other respiratory parameters (Miller \& Awe 1975, Weiss \& Patwardhan 1977, Fish \& Peterman 1979, McAlpine \& Thomson 1989, Bulut et al. 1996). Bronchoconstriction following lidocaine inhalation was also assessed using high-resolution computed tomography in Basenji-Greyhound dogs with hyperreactive airways (Bulut et al. 1996). Analyzing airway caliber before and after the administration of lidocaine aerosol, a 27\% decrease from baseline was observed. Intravenous administration of lidocaine did no cause airway changes but clearly prevented initial broncoconstriction evoked by aerosolized lidocaine in these animals (Bulut et al. 1996). In asthmatics, bronchoconstriction caused by lidocaine aerosol was clearly reversed with aerosolized atropine, isoproterenol (Fish \& Peterman 1979) or sabutamol (Harrison \& Tattersfield 1998, Groeben et al. 2000). Moreover, combined lidocaine and salbutamol inhalation protected against histamine-evoked bronchoconstriction in mild asthmatics to a much greater extent than pretreatment with either drug alone (Groeben et al. 2000). These findings pointed out that in the case of using lidocaine for the control of asthma, the treatment should be accompanied by a $\beta$-adrenergic aerosol. The combined inhalation might prevent the putative irritant effects of lidocaine, and yield an improved bronchial hyperreactivity blockade due to the synergistic interaction of these substances (Harrison \& Tattersfield 1998, Groeben et al. 2000).

Several mechanisms may explain the attenuation of bronchoconstriction by lidocaine but none of them has been definitively proven in vivo. Aerosolized lidocaine is theoretically capable of blocking neurogenic reflexes in the lung, and the neural blockade of vagal reflex pathways may indeed explain its ability to attenuate the response to different stimuli evoking bronchoconstriction (Enright et al. 1980, Makker \& Holgate 1993, Groeben et al. 2000). Actually, the lidocaine protective effect occurs at plasma concentrations much lower than those required for intravenous lidocaine to impair airway broncoconstriction, in line with the interpretation that this effect is accounted for by topical airway anaesthesia. If this is the case, the protective effect should be presumably independent of the local anaesthetic used. While trying to clarify this point, Gloeben et al. (2001) tested three local anaesthetics with distinct anaesthetic potencies (Groeben et al. 2001). They reported that inhaled lidocaine and ropivacaine significantly attenuated histamine-evoked bronchoconstriction whereas dyclonine, despite its longer lasting and more intense local anaesthesia, did not. In addition, inhaled dyclonine was by far the most irritant for the airways (Groeben et al. 2001). These findings were double-folded illustrative. First because they made clear that the protective effect of lidocaine on bronchospasm might indeed be dissociated from its local anaesthetic activity. Second because they raised the possibility that lung anaesthesia might indeed account for the airway irritant properties of this class of agents.

Lidocaine effects on bronchial hypearreactivity might also be accounted for by a direct relaxant effect on airway smooth muscle (Downes \& Loehning 1977, Weiss et al. 1978, Okumura \& Denborough 1980, Kai et al. 1993). Kai et al. (1993) reported that lidocaine had direct spasmolytic properties by inhibition of calcium influx and release of stored calcium. Accordingly, circulating concentrations of lidocaine of more than $100 \mu \mathrm{M}$ had marked airway relaxant effects (Kai et al. 1993).

\section{Conclusion}

There is renewed interest in lidocaine for treatment of atopic asthma. Inhaled lidocaine has glucocorticosteroidsparing properties in atopic asthmatics as demonstrated by significant reduction in symptoms, bronchodilator use and blood eosinophilia. Lidocaine has marked effects in several settings beyond neuronal blockade, and some of these alternative actions may also be beneficial to asthma control. There is clear evidence for anti-inflammatory and spasmolitic properties. Inhibitory effects of lidocaine on eosinophil survival and activation, mast cell secretor function, as well as CD4+ T-cell proliferation and cytokine generation, seem to be most important. Lidocaine also significantly attenuates the response to direct stimulation of airway smooth fibers in a mechanism closely associated with blockade of calcium influx. On the other hand, inhalation of lidocaine initially evokes a significant decrease in $\mathrm{FEV}_{1}$ in the majority of asthmatic volunteers, an effect sensitive to $\beta_{2}$-agonist pretreatment. As in the case of glucocorticosteroid therapy, treatment with combination inhalers, containing lidocaine and a long-acting $\beta_{2}$ agonist, may turn out to be the safer and more reliable alternative. In addition, since airway anesthesia alone does not necessarily attenuate bronchial hyperreativity, further research should be directed to (i) clarify the mode of action of lidocaine on both inflammation and airway obstruction and (ii) structure-activity studies, particularly concerning non anaesthetic lidocaine analogues.

\section{REFERENCES}

Apter AJ, Szefler SJ 2004. Advances in adult and pediatric asthma. J Allergy Clin Immunol 113: 407-414.

Bankers-Fulbright JL, Kephart GM, Loegering DA, Bradford AL, Okada S, Kita H, Gleich GJ 1998. Sulfonylureas inhibit cytokine-induced eosinophil survival and activation. J Immunol 160: 5546-5553.

Barnes PJ 2004. New drugs for asthma. Nat Rev Drug Discov 3: 831-844. 
Bulut Y, Hirshman CA, Brown RH 1996. Prevention of lidocaine aerosol-induced bronchoconstriction with intravenous lidocaine. Anesthesiology 85: 853-859.

Busse WW, Rosenwasser LJ 2003. Mechanisms of asthma. $J$ Allergy Clin Immunol 111: S799-804.

Caplan RA, Posner KL, Ward RJ, Cheney FW 1990. Adverse respiratory events in anesthesia: a closed claims analysis. Anesthesiology 72: 828-833.

Caramori G, Adcock I 2003. Pharmacology of airway inflammation in asthma and COPD. Pulm Pharmacol Ther 16: 247-277.

Decco ML, Neeno TA, Hunt LW, O’Connell EJ, Yunginger JW, Sachs MI 1999. Nebulized lidocaine in the treatment of severe asthma in children: a pilot study. Ann Allergy Asthma Immunol 82: 29-32.

Downes H, Loehning RW 1977. Local anesthetic contracture and relaxation of airway smooth muscle. Anesthesiology 47: 430-436.

Ellis C 2003. FDA alerts asthmatics to drug safety risk. Nat Rev Drug Discov 2: 765.

Enright PL, McNally JF, Souhrada JF 1980. Effect of lidocaine on the ventilatory and airway responses to exercise in asthmatics. Am Rev Respir Dis 122: 823-828.

Fish JE, Peterman VI 1979. Effects of inhaled lidocaine on airway function in asthmatic subjects. Respiration 37: 201207.

Groeben H, Grosswendt T, Silvanus MT, Pavlakovic G, Peters J 2001. Airway anesthesia alone does not explain attenuation of histamine-induced bronchospasm by local anesthetics: a comparison of lidocaine, ropivacaine, and dyclonine. Anesthesiology 94: 423-428.

Groeben H, Silvanus MT, Beste M, Peters J 1999. Both intravenous and inhaled lidocaine attenuate reflex bronchoconstriction but at different plasma concentrations. Am J Respir Crit Care Med 159: 530-535.

Groeben H, Silvanus MT, Beste M, Peters J 2000. Combined lidocaine and salbutamol inhalation for airway anesthesia markedly protects against reflex bronchoconstriction. Chest 118: 509-515.

Harrison TW, Tattersfield AE 1998. Effect of single doses of inhaled lignocaine on FEV1 and bronchial reactivity in asthma. Respir Med 92: 1359-1363.

Hollmann MW, Durieux ME 2000. Local anesthetics and the inflammatory response: a new therapeutic indication? Anesthesiology 93: 858-875.

Hunt LW, Frigas E, Butterfield JH, Kita H, Blomgren J, Dunnette SL, Offord KP, Gleich GJ 2004. Treatment of asthma with nebulized lidocaine: a randomized, placebo-controlled study. J Allergy Clin Immunol 113: 853-859.

Hunt LW, Swedlund HA, Gleich GJ 1996. Effect of nebulized lidocaine on severe glucocorticoid-dependent asthma. Mayo Clin Proc 71: 361-368.

Illek B, Fischer H, Kreusel KM, Hegel U, Clauss W 1992. Volume-sensitive basolateral K+ channels in HT-29/B6 cells: block by lidocaine, quinidine, NPPB, and $\mathrm{Ba} 2+$. Am J Physiol 263: C674-683.

Kai T, Nishimura J, Kobayashi S, Takahashi S, Yoshitake J,
Kanaide H 1993. Effects of lidocaine on intracellular Ca2+ and tension in airway smooth muscle. Anesthesiology 78: 954-965.

Kay AB 2003. Immunomodulation in asthma: mechanisms and possible pitfalls. Curr Opin Pharmacol 3: 220-226.

Lazarus SC, Boushey HA, Fahy JV, Chinchilli VM, Lemanske Jr RF, Sorkness CA, Kraft M, Fish JE, Peters SP, Craig T, Drazen JM, Ford JG, Israel E, Martin RJ, Mauger EA, Nachman SA, Spahn JD, Szefler SJ 2001. Long-acting beta2agonist monotherapy vs continued therapy with inhaled corticosteroids in patients with persistent asthma: a randomized controlled trial. Jama 285: 2583-2593.

Loehning RW, Waltemath CL, Bergman NA 1976. Lidocaine and increased respiratory resistance produced by ultrasonic aerosols. Anesthesiology 44: 306-310.

Makker HK, Holgate ST 1993. The contribution of neurogenic reflexes to hypertonic saline-induced bronchoconstriction in asthma. J Allergy Clin Immunol 92: 82-88.

McAlpine LG, Thomson NC 1989. Lidocaine-induced bronchoconstriction in asthmatic patients. Relation to histamine airway responsiveness and effect of preservative. Chest 96: 1012-1015.

Miller WC, Awe R 1975. Effect of nebulized lidocaine on reactive airways. Am Rev Respir Dis 111: 739-741.

Ohnishi T, Kita H, Mayeno AN, Okada S, Sur S, Broide DH, Gleich GJ 1996. Lidocaine in bronchoalveolar lavage fluid (BALF) is an inhibitor of eosinophil-active cytokines. Clin Exp Immunol 104: 325-331.

Okada S, Hagan JB, Kato M, Bankers-Fulbright JL, Hunt LW, Gleich GJ, Kita H 1998. Lidocaine and its analogues inhibit IL-5-mediated survival and activation of human eosinophils. J Immunol 160: 4010-4017.

Okumura F, Denborough MA 1980. Effects of anaesthetics on guineapig tracheal smooth muscle. Br J Anaesth 52: 199204.

Olschewski A, Brau ME, Olschewski H, Hempelmann G, Vogel W 1996. ATP-dependent potassium channel in rat cardiomyocytes is blocked by lidocaine. Possible impact on the antiarrhythmic action of lidocaine. Circulation 93: 656-659.

Payne DN, Rogers AV, Adelroth E, Bandi V, Guntupalli KK, Bush A, Jeffery PK 2003. Early thickening of the reticular basement membrane in children with difficult asthma. Am J Respir Crit Care Med 167: 78-82.

Redding GJ, Stoloff SW 2004. Changes in recommended treatments for mild and moderate asthma. J Fam Pract 53: 692700 .

Rosario NA, Riedi CA, Farias L 2000. Lidocaine nebulization for treatment of asthma. Ann Allergy Asthma Immunol 85: 245-246.

Sears MR 2002. Adverse effects of beta-agonists. J Allergy Clin Immunol 110: S322-328.

Shore SA, Drazen JM 2003. Beta-agonists and asthma: too much of a good thing? J Clin Invest 112: 495-497.

Tanaka A, Minoguchi K, Oda N, Yokoe T, Matsuo H, Okada S, Tasaki T, Adachi M 2002. Inhibitory effect of lidocaine on $\mathrm{T}$ cells from patients with allergic asthma. J Allergy Clin Immunol 109: 485-490. 
Tetzlaff JE 2000. The pharmacology of local anesthetics. Anesthesiol Clin North America 18: 217-233.

Umetsu DT, McIntire JJ, Akbari O, Macaubas C, DeKruyff RH 2002. Asthma: an epidemic of dysregulated immunity. Nat Immunol 3: 715-720.

Weiss EB, Hargraves WA, Viswanath SG 1978. The inhibitory action of lidocaine in anaphylaxis. Am Rev Respir Dis 117:
859-869.

Weiss EB, Patwardhan AV 1977. The response to lidocaine in bronchial asthma. Chest 72: 429-438.

Yoneda I, Sakuta H, Okamoto K, Watanabe Y 1993. Effects of local anesthetics and related drugs on endogenous glibenclamide-sensitive $\mathrm{K}+$ channels in Xenopus oocytes. Eur J Pharmacol 247: 267-272. 
